Research Paper

\title{
The association between RFCl G80A polymorphism and cancer susceptibility: Evidence from 33 studies
}

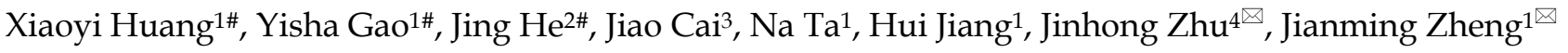 \\ 1. Department of Pathology, Changhai Hospital, Second Military Medical University, Shanghai 200433, China \\ 2. Department of Pediatric Surgery, Guangzhou Women and Children's Medical Center, Guangzhou Medical University, Guangzhou 510623, Guangdong, \\ China \\ 3. Department of Pathophysiology, Second Military Medical University, Shanghai 200433, China \\ 4. Molecular Epidemiology Laboratory and Department of Laboratory Medicine, Harbin Medical University Cancer Hospital, Harbin 150040, Heilongjiang, \\ China \\ \# Xiaoyi Huang, Yisha Gao and Jing He contributed equally to this work. \\ $\square$ Corresponding authors: Jianming Zheng, Department of Pathology, Changhai Hospital, Second Military Medical University, 168 Changhai Road, Shanghai \\ 200438, China, Tel /Fax: (+86-021) 81873689, E-mail: jmzheng1962@smmu.edu.cn; Jinhong Zhu, Molecular Epidemiology Laboratory and Department of Labor- \\ atory Medicine, Harbin Medical University Cancer Hospital, 150 Haping Road, Harbin 150040, Heilongjiang, China, Tel: (+86-0451) 86298786, Fax: (+86-0451) \\ 86298398, E-mail: jinhongzhu625@gmail.com
}

(1) Ivyspring International Publisher. Reproduction is permitted for personal, noncommercial use, provided that the article is in whole, unmodified, and properly cited. See http://ivyspring.com/terms for terms and conditions.

Received: 2015.07.21; Accepted: 2015.10.18; Published: 2016.01.01

\begin{abstract}
Aberrant folate metabolism is closely related to tumorigenesis. Genetic variations in the Reduced folate carrier I (RFCl) may alter the progress of folate metabolism, and thereby cause the initiation and progress of the cancer. Considerable studies have performed to investigate the association between RFCl G80A (rs1051266) polymorphism and cancer susceptibility, but the conclusions were conflicting. Therefore, we conducted a meta-analysis to reevaluate the association of $R F C l$ G80A polymorphism with cancer risk. PubMed and EMBASE were searched for eligible studies. The association of $R F C l$ G80A polymorphism and cancer risk was evaluated by the pooled odds ratios (ORs) and corresponding $95 \%$ confidence intervals ( $\mathrm{Cls}$ ). The significant association was found between $\mathrm{RFCl} \mathrm{G} 80 \mathrm{~A}$ polymorphism and hematological malignance susceptibility (A vs. G: $\mathrm{OR}=1.11,95 \% \mathrm{Cl}=1.003-1.23, P=0.045 ; \mathrm{GA}$ vs. $\mathrm{GG}: \mathrm{OR}=1.18,95 \% \mathrm{Cl}=1.06-1.31, P=0.002$; $\mathrm{AA}+\mathrm{GA}$ vs. GG: $O R=1.18,95 \% \mathrm{Cl}=1.07-1.29, P=0.001)$. Stratified analysis by ethnicity indicated that the association became more prominent among Caucasians (GA vs. GG: $\mathrm{OR}=1.28,95 \% \mathrm{Cl}=1.12-1.45$, $P<0.001 ; A A+G A$ vs. $G G: O R=1.21,95 \% C l=1.08-1.36, P=0.001)$. In term of the cancer type, this polymorphism significantly increased the risk of acute lymphoblast leukemia (GA vs. GG: $O R=1.13,95 \% \mathrm{Cl}=1.001-1.28, P=0.048 ; A A+G A$ vs. $G G: O R=1.28,95 \% C l=1.13-1.46, P<0.001)$ and acute myeloid leukemia (GA vs. GG: $O R=2.57,95 \% \mathrm{Cl}=1.37-4.85, P=0.003$ ). No significant association between $\mathrm{RFCl} \mathrm{G} 80 \mathrm{~A}$ polymorphism and overall solid cancer risk was observed, but a protective association with digestive cancer risk was found (GA vs. GG: $O R=0.89,95 \% \mathrm{Cl}=$ $0.81-0.99, P=0.030$ ). The comprehensive meta-analysis encouraged the notion that $R F C l$ G80A polymorphism may play an important role in hematopoietic system malignance. These findings need further validation in the large multicenter investigations.
\end{abstract}

Key words: reduced folate carrier 1 gene; polymorphism; cancer susceptibility; meta-analysis

\section{Introduction}

Cancer, one of the leading causes of death all around the world, is a result of multiple environmental and genetic risk factors, as well as gene-environment interactions. According to the cancer statistics, approximately 1658370 new cancer may occur in USA in 2015 [1]. Although substantial resources have been dedicated to cancer research, cancer is still a huge threat to human. It is well known 
that both environmental and hereditary factors play critical roles in the initiation and progression of cancer [2]. Among genetic factors, genetic mutation and epigenetic change such as DNA methylation can lead to carcinogenesis [3]. One-carbon metabolism is closely related to DNA methylation, in which folate, a member of water-soluble B vitamins family [4], plays an important role $[5,6]$. Folate is an essential material in cell proliferation and tissue regeneration $[7,8]$, which cannot be synthesized in the mammalian cell, and must be obtained from extracellular environment to support one-carbon transfer biosynthetic reactions [9]. Folate deficiency can result in DNA hypomethylation and gene instability and subsequently induce disease by changing gene expression and increasing DNA impairment. Studies have shown that folate metabolism dysfunction are implicated in a variety of diseases, such as neuroblastoma [10], breast cancer [11], non-Hodgkin lymphoma [12, 13], and neural tube defect [14]. Given the crucial role of folate, its transporters including folate receptors (FRs), proton-coupled folate transporter (PCFT) and reduced folate carrier (RFC) are of great importance to the maintenance of hemostasis humans [15].

Reduced folate carrier 1 (RFC1)/ solute carrier family 19 members 1 (SLC19A1) gene, located on chromosome 21 , encodes a folate transport protein that has been considered as one of the major components of folate transport system $[15,16]$. Besides, RFC1 also plays a part in antifolate transportation during chemotherapy [17], and RFC1 gene variation can affect the outcome and toxicity of methotrexate (MTX) therapy in leukemia [18]. RFC1 G80A polymorphism located in exon 2 leads to an amino acid substitution of histidine for the arginine at codon 27 (H27R) of RFC1.This polymorphism may influence the function of RFC and one-carbon metabolism, thereby inducing tumorigenesis [19]. Lack of folate leads to DNA synthesis disorders and therefore causes genomic instability. Thus, RFC1 G80A polymorphism can affect DNA synthesis in the pathogenesis of cancer. Previously, RFC1 G80A polymorphism had been proven to be a risk factor of acute lymphoblastic leukemia in some studies [20], but other studies showed that RFC1 G80A polymorphism was not related to the risk of acute lymphoblastic leukemia [21]. Moreover, the impact of RFC1 G80A polymorphism on solid cancer risk was not definitely known. Recently, several studies have explored the association between RFC1 G80A polymorphism and solid tumor, including colorectal cancer [22-25], gastroesophageal cancer [26], bladder cancer [27], breast cancer [28-31] and nervous system cancer [32]. Naushad et al. [30] found that RFC1 G80A polymorphism conferred increased susceptibility to breast cancer, while De Cassia Carvalho
Barbosa et al. [31] indicated that the same polymorphism had the protective effect on breast cancer. The association between RFC1 G80A polymorphism and cancer risk was controversy. Therefore, it is necessary to conduct a comprehensive analysis to clarify the association.

\section{Materials and Methods}

\section{Literature search strategy}

The PubMed and EMBASE were searched thoroughly without any language restriction to seek potential studies. The following keywords were used for literature search: "RFC, reduced folate carrier gene, rs1051266, RFC1 G80A, or SLC19A1", "polymorphism, variant, or variation", and "cancer, neoplasm, or carcinoma". Additionally, literature was searched by manually screening the reference lists of the eligible studies and reviews. The last search was performed on March 31, 2015.

\section{Inclusion and exclusion criteria}

The articles included met the following criteria: (a) studies focused on the association between RFC1 G80A polymorphism and cancer risk; (b) case-control studies or other observational studies; (c) studies providing the genotype distribution data or other original data that can be used to calculate genotype distribution. Exclusion criteria were as follows: (a) duplicate studies; (b) lack of enough data of genotype distribution or data for deducing genotype distribution; (c) not case-control studies.

\section{Study selection and Data extraction}

Two investigators extracted data from eligible articles separately. The following data were extracted from the original articles: (1) authors, (2) year of publication, (3) country in which study was conducted, (4) ethnicity, (5) type of cancer, (6) sample size, and (7) alleles and genotypes distribution. When argument occurred between the two investigators, the disagreements were solved by the third investigator. The disagreements were fully discussed by all the three investigators and then vote by ballot among all the researchers.

\section{Statistical analysis}

All genotypes frequency of RFC1 G80A polymorphism was calculated and chi-square test was employed to assess the Hardy-Weinberg Equilibrium (HWE) in control subjects for every study. The association between RFC1 G80A polymorphism and cancer risk was assessed by calculating pooled odds ratio $(\mathrm{OR})$ and 95\% confidence interval (CI) under the five genetic models: comparisons of allele frequencies, homozygous, heterozygous, dominant, and recessive 
models. All the statistical tests were two-sided and the result with $P<0.05$ was regarded as a statistically significant. $Q$ value and $I^{2}$ were used to evaluate the between-study heterogeneity in the heterogeneity test. The random effects model were hired to calculate the pooled OR and $95 \%$ CI when $\mathrm{I}^{2}>50 \%$. Otherwise, the fixed effect model was adopted. Moreover, subgroup analyses were performed according to ethnicity and cancer type. Subsequently, the sensitivity analysis was performed by successively removing one study at a time to recalculate OR and 95\% CI. Publication bias was assessed by funnel plots and Egger's linear regression test. If the funnel plots were asymmetry or $P<0.1$, publication bias was considered significant. All the results above were performed by STATA 12.0 (STATA Corporation, College Station, TX).

\section{Results}

\section{Search results and study characteristics}

Using the keywords, 454 and 240 articles were retrieved from PubMed and EMBASE, respectively. Most of studies were excluded after carefully reading the titles and abstracts. The remaining articles were further evaluated by reading through the text. As a result, 28 eligible articles were included in the meta-analysis. Additionally, 2 articles were found through manually searching the reference lists of the eligible studies and reviews. In total, the meta-analysis contained 30 articles consisting of 33 studies with 12020 cases and 14343 controls, focusing on the relationship between RFC1 G80A polymorphism and cancer risk (Figure 1). The characteristics of the studies included in the meta-analysis are shown in Table 1.

Table 1. The characteristics of the included studies on RFCI G80A polymorphism and cancer risk

\begin{tabular}{|c|c|c|c|c|c|c|c|c|c|c|c|}
\hline Author & Year & Ethnicity & Country & Cancer type & Sample size & & Case & & & Contr & \\
\hline & & & & & Cases/Controls & GG & GA & AA & GG & GA & AA \\
\hline Whetstine[44] & 2001 & Caucasian & USA & ALL & $54 / 51$ & 10 & 24 & 20 & 9 & 25 & 17 \\
\hline Skibola[45] & 2004 & Caucasian & USA & non-Hodgkin lymphoma & $334 / 729$ & 109 & 158 & 67 & 266 & 331 & 132 \\
\hline Ulrich[22] & 2005 & Mixed & USA & colorectal cancer & $1600 / 1962$ & 513 & 788 & 299 & 585 & 976 & 401 \\
\hline Lightfoot[46] & 2005 & Caucasian & USA & non-Hodgkin lymphoma & $589 / 755$ & 199 & 277 & 113 & 263 & 369 & 123 \\
\hline Wang[26] & 2006 & Asian & China & oesophageal cancer & $216 / 673$ & 66 & 67 & 83 & 193 & 313 & 167 \\
\hline Wang[26] & 2006 & Asian & China & gastric cancer & $633 / 673$ & 177 & 242 & 214 & 193 & 313 & 167 \\
\hline Moore[27] & 2007 & Caucasian & Spain & bladder cancer & $1084 / 1032$ & 301 & 520 & 263 & 313 & 500 & 219 \\
\hline $\mathrm{Xu}[28]$ & 2007 & Caucasian & USA & breast cancer & $1066 / 1108$ & 247 & 532 & 287 & 237 & 561 & 310 \\
\hline Gast[47] & 2007 & Caucasian & Germany & ALL & $542 / 542$ & 125 & 251 & 79 & 178 & 256 & 108 \\
\hline Eklof[23] & 2008 & Caucasian & Sweden & colorectal cancer & $219 / 410$ & 70 & 93 & 56 & 116 & 190 & 104 \\
\hline Kotsopoulos[29] & 2008 & Caucasian & Canada & breast cancer & $937 / 764$ & 304 & 440 & 193 & 243 & 347 & 174 \\
\hline Liu[48] & 2008 & Asian & China & lung cancer & $499 / 504$ & 127 & 250 & 122 & 137 & 250 & 117 \\
\hline Sirachainan[32] & 2008 & Asian & Thailand & central nervous system tumors & $73 / 205$ & 18 & 38 & 17 & 44 & 104 & 57 \\
\hline Di[40] & 2009 & Asian & China & cervical cancer & $107 / 107$ & 31 & 48 & 28 & 18 & 46 & 43 \\
\hline de Jonge[49] & 2009 & Caucasian & Netherland & ALL & $241 / 495$ & 69 & 120 & 52 & 186 & 241 & 68 \\
\hline Kurzwelly[50] & 2010 & Caucasian & Germany & $\begin{array}{l}\text { primary central nervous system } \\
\text { lymphoma }\end{array}$ & $185 / 212$ & 68 & 87 & 30 & 76 & 91 & 45 \\
\hline Yeoh[51] & 2010 & Asian & $\begin{array}{l}\text { Malay- } \\
\text { sia-Singapore }\end{array}$ & ALL & $210 / 319$ & 62 & 108 & 40 & 72 & 170 & 77 \\
\hline Curtin[24] & 2011 & Mixed & USA & colorectal cancer & $724 / 922$ & 226 & 351 & 147 & 280 & 459 & 183 \\
\hline Galbiatti[41] & 2011 & Caucasian & Brazil & $\begin{array}{l}\text { head and neck aquamous cell } \\
\text { carcinoma }\end{array}$ & $322 / 531$ & 92 & 137 & 93 & 126 & 221 & 184 \\
\hline Jokic[25] & 2011 & Caucasian & Croatia & colorectal cancer & $300 / 300$ & 85 & 160 & 55 & 90 & 155 & 55 \\
\hline Naushad[30] & 2011 & Asian & India & breast cancer & $244 / 244$ & 87 & 107 & 50 & 96 & 122 & 26 \\
\hline Chan[20] & 2011 & Asian & Singapore & ALL & $184 / 177$ & 43 & 98 & 43 & 61 & 75 & 41 \\
\hline Metayer[21] & 2011 & Caucasian & USA & ALL & $348 / 422$ & 106 & 188 & 54 & 132 & 205 & 85 \\
\hline Yang[52] & 2011 & Asian & China & ALL & $361 / 367$ & 93 & 172 & 96 & 105 & 191 & 71 \\
\hline Zhao[53] & 2011 & Asian & China & ALL & $98 / 135$ & 21 & 53 & 24 & 53 & 52 & 30 \\
\hline De Cassia[31] & 2012 & Caucasian & Brazil & breast cancer & $156 / 156$ & 58 & 71 & 27 & 30 & 89 & 37 \\
\hline Silva[38] & 2013 & Caucasian & Brazil & AML & $21 / 137$ & 4 & 10 & 7 & 49 & 56 & 32 \\
\hline Silva[38] & 2013 & Caucasian & Brazil & ALL & $95 / 137$ & 21 & 38 & 36 & 49 & 56 & 32 \\
\hline De Miranda[37] & 2014 & Caucasian & Brazil & central nervous system tumors & $30 / 92$ & 4 & 14 & 12 & 31 & 43 & 18 \\
\hline Karathanasis[54] & 2014 & Caucasian & Greece & ALL & $35 / 48$ & 9 & 16 & 10 & 15 & 18 & 15 \\
\hline Suthandiram[55] & 2014 & Asian & Malaysia & non-Hodgkin lymphoma & $372 / 722$ & 99 & 182 & 91 & 187 & 354 & 181 \\
\hline Montalvao[39] & 2015 & Caucasian & Brazil & nephroblastoma & $77 / 222$ & 13 & 38 & 26 & 76 & 103 & 43 \\
\hline Montalvao[39] & 2015 & Caucasian & Brazil & central nervous system tumors & $64 / 222$ & 11 & 33 & 20 & 76 & 103 & 43 \\
\hline
\end{tabular}

ALL, acute lymphoblast leukemia; AML, acute myeloid leukemia 


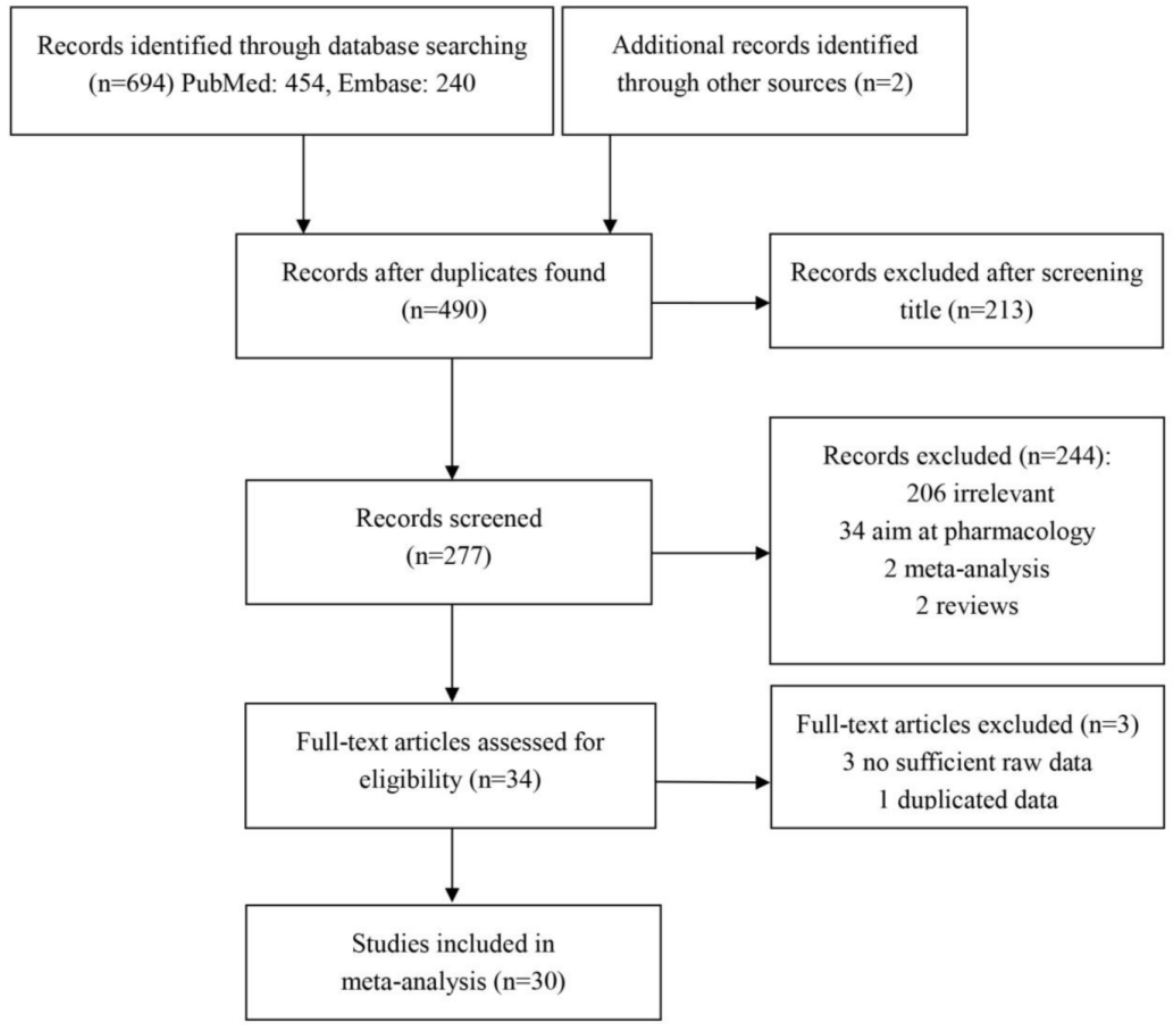

Figure 1. Flow chart of the study selection and inclusion process.

\section{Meta-analysis results}

Since the pathogenesis of solid cancer and hematological malignance vary greatly, we explored the association of RFC1 G80A polymorphism with solid cancer and hematological malignance separately. The pooled ORs and 95\% CIs indicated that there was no significant association between RFC1 G80A polymorphism and overall solid cancer risk (Figure 2). When stratified by cancer type, subgroup analysis indicated that RFC1 G80A polymorphism was associated with the decreased risk of digestive system cancer under the heterozygous model $(\mathrm{OR}=0.89$, $95 \% \mathrm{CI}=0.81-0.99, P=0.03$ ), while no significant association was detected for other cancer types (Table 2). However, RFC1 G80A polymorphism was shown to significantly increase the risk of developing hematological malignance (comparisons of allele frequencies: A vs. $G$ : $O R=1.11,95 \% \mathrm{CI}=1.003-1.23, P=0.045$; heterozygous: GA vs. GG: $\mathrm{OR}=1.18,95 \% \mathrm{CI}=1.06-1.31$, $P=0.002$; dominant: $\mathrm{AA}+\mathrm{GA}$ vs. $\mathrm{GG}: \mathrm{OR}=1.18$, $95 \% \mathrm{CI}=1.07-1.29, P=0.001)$, as are shown in Figure 3 . Moreover, stratification analysis was performed by cancer type and ethnicity, as shown in Table 3. The association became stronger among Caucasians, but not valid among Asians (GA vs. GG: $O R=1.28$, 95\% CI=1.12-1.45, $P<0.001$; AA+GA vs. GG: $\mathrm{OR}=1.21$,
95\% CI=1.08-1.36, $P=0.001$ ). With respect to cancer type, the studied polymorphism imparted increased genetic susceptibility to ALL (GA vs. GG: $\mathrm{OR}=1.13$, 95\% CI=1.001-1.28, $P=0.048$; AA+GA vs. GG: $\mathrm{OR}=1.28$, 95\% CI $=1.13-1.46, P<0.001$ ) and AML (GA vs. GG: $\mathrm{OR}=2.57,95 \% \mathrm{CI}=1.37-4.85, P=0.003)$.

\section{Sensitive analysis and publication bias}

The funnel plot and Egger's test were conducted to test publication biases. The funnel plots of the association between RFC1 G80A polymorphism and solid cancer and hematological malignance were symmetrical in the allele model (Figure 4 and Figure 5). The Egger's test value indicated that there was no significant publication bias in our meta-analysis $(P=0.304 ; 0.287 ; 0.768 ; 0.476$ and 0.273 for allele, homozygous, heterozygous, dominant and recessive models of RFC1 G80A polymorphism and solid cancer risk respectively; $P=0.219 ; 0.374 ; 0.183 ; 0.201 ; 0.686$ for allele, homozygous, heterozygous, dominant, and recessive models of RFC1 G80A polymorphism and hematological malignance respectively). The sensitive analyses indicated that no single study could qualitatively change the results, suggesting the robustness of the meta-analysis. 
Table 2. Meta-analysis of RFCl G80A polymorphism and solid cancer

\begin{tabular}{|c|c|c|c|c|c|c|c|c|c|c|c|c|c|c|c|}
\hline \multirow[t]{2}{*}{ Variables } & \multicolumn{3}{|c|}{ A vs. $G$} & \multicolumn{3}{|c|}{ AA vs. GG } & \multicolumn{3}{|c|}{ GA vs. GG } & \multicolumn{3}{|c|}{ AA+GA vs. GG } & \multicolumn{3}{|c|}{ AA vs. AG+GG } \\
\hline & OR & $95 \% \mathrm{CI}$ & $\mathrm{P}$ & OR & $95 \% \mathrm{CI}$ & $\mathrm{P}$ & OR & $95 \% \mathrm{CI}$ & $\mathrm{P}$ & OR & $95 \% \mathrm{CI}$ & $\mathrm{P}$ & OR & $95 \% \mathrm{CI}$ & $\mathrm{P}$ \\
\hline Overall & 1.04 & $0.94-1.14$ & 0.439 & 1.08 & $0.90-1.29$ & 0.432 & 0.94 & $0.88-1.01$ & 0.102 & 0.98 & $0.87-1.10$ & 0.727 & 1.12 & $0.96-1.30$ & 0.155 \\
\hline \multicolumn{16}{|l|}{ Ethnicity } \\
\hline Mixed & 0.94 & $0.87-1.02$ & 0.144 & 0.89 & $0.76-1.05$ & 0.164 & 0.93 & $0.82-1.05$ & 0.249 & 0.92 & $0.82-1.03$ & 0.161 & 0.94 & $0.82-1.07$ & 0.343 \\
\hline Caucasian & 1.06 & $0.91-1.23$ & 0.469 & 1.10 & $0.83-1.47$ & 0.500 & 0.99 & $0.90-1.09$ & 0.838 & 1.04 & $0.83-1.29$ & 0.760 & 1.06 & $0.89-1.28$ & 0.510 \\
\hline Asian & 1.07 & $0.89-1.27$ & 0.485 & 1.15 & $0.82-1.62$ & 0.429 & 0.87 & $0.74-1.01$ & 0.063 & 0.99 & $0.84-1.16$ & 0.899 & 1.24 & $0.88-1.75$ & 0.213 \\
\hline \multicolumn{16}{|l|}{ Cancer type } \\
\hline Digestive system cancer & 1.04 & $0.93-1.17$ & 0.456 & 1.07 & $0.88-1.31$ & 0.497 & 0.89 & 0.81-0.99 & 0.030 & 0.94 & $0.86-1.03$ & 0.200 & 1.18 & $0.92-1.51$ & 0.194 \\
\hline Urinary system cancer & 1.41 & $0.85-2.63$ & 0.187 & 1.97 & $0.72-5.51$ & 0.190 & 1.15 & $0.95-1.39$ & 0.165 & 1.60 & $0.73-3.53$ & 0.245 & 1.49 & $0.86-2.59$ & 0.159 \\
\hline Breast cancer & 0.94 & $0.77-1.15$ & 0.539 & 0.91 & $0.59-1.40$ & 0.677 & 0.91 & $0.79-1.04$ & 0.163 & 0.86 & $0.64-1.14$ & 0.285 & 1.02 & $0.74-1.40$ & 0.903 \\
\hline Central nervous system tumors & 1.48 & $0.82-2.68$ & 0.194 & 2.16 & $0.66-7.09$ & 0.206 & 1.50 & $0.96-2.35$ & 0.078 & 1.78 & $0.74-4.27$ & 0.197 & 1.53 & $0.74-3.16$ & 0.248 \\
\hline Others & 0.81 & $0.66-0.98$ & 0.204 & 0.72 & $0.43-1.22$ & 0.224 & 0.93 & $0.75-1.15$ & 0.513 & 0.82 & $0.56-1.19$ & 0.289 & 0.81 & $0.57-1.14$ & 0.226 \\
\hline
\end{tabular}

Table 3. Meta-analysis of RFCI G80A polymorphism and hematological malignance

\begin{tabular}{|c|c|c|c|c|c|c|c|c|c|c|c|c|c|c|c|}
\hline \multirow[t]{2}{*}{ Variables } & \multicolumn{3}{|c|}{ A vs. G } & \multicolumn{3}{|c|}{ AA vs. GG } & \multicolumn{3}{|c|}{ GA vs. GG } & \multicolumn{3}{|c|}{ AA+GA vs. GG } & \multicolumn{3}{|c|}{ AA vs. AG+GG } \\
\hline & OR & $95 \% \mathrm{CI}$ & $\mathrm{P}$ & OR & $95 \% \mathrm{CI}$ & $\mathrm{P}$ & OR & $95 \% \mathrm{CI}$ & $\mathrm{P}$ & OR & $95 \% \mathrm{CI}$ & $\mathrm{P}$ & OR & $95 \% \mathrm{CI}$ & $\mathrm{P}$ \\
\hline Overall & 1.11 & $1.00-1.23$ & 0.045 & 1.21 & $0.99-1.47$ & 0.063 & 1.18 & $1.06-1.31$ & 0.002 & 1.18 & $1.07-1.29$ & 0.001 & 1.07 & $0.90-1.27$ & 0.439 \\
\hline \multicolumn{16}{|l|}{ Ethnicity } \\
\hline Caucasian & 1.12 & $0.99-1.26$ & 0.070 & 1.24 & $0.97-1.58$ & 0.092 & 1.28 & $1.12-1.45$ & $<0.001$ & 1.21 & $1.08-1.36$ & 0.001 & 1.09 & $0.86-1.38$ & 0.493 \\
\hline Asian & 1.10 & $0.90-1.34$ & 0.372 & 1.17 & $0.80-1.71$ & 0.424 & 1.01 & $0.84-1.22$ & 0.898 & 1.11 & $0.94-1.31$ & 0.212 & 1.05 & $0.82-1.34$ & 0.696 \\
\hline \multicolumn{16}{|l|}{ Cancer type } \\
\hline ALL & 1.15 & $0.99-1.34$ & 0.069 & 1.29 & $0.96-1.79$ & 0.095 & 1.13 & $1.00-1.28$ & 0.048 & 1.28 & $1.13-1.46$ & $<0.001$ & 1.09 & $0.84-1.40$ & 0.537 \\
\hline NHL & 1.06 & $0.96-1.17$ & 0.245 & 1.13 & $0.93-1.38$ & 0.228 & 1.16 & $0.88-1.52$ & 0.285 & 1.06 & $0.92-1.23$ & 0.425 & 1.10 & $0.93-1.31$ & 0.266 \\
\hline PCNSL & 0.89 & $0.67-1.18$ & 0.398 & 0.75 & $0.42-1.31$ & 0.308 & 1.34 & $0.94-1.91$ & 0.102 & 0.96 & $0.64-1.45$ & 0.851 & 0.72 & $0.43-1.20$ & 0.204 \\
\hline AML & 1.71 & $0.89-3.30$ & 0.109 & 2.68 & $0.73-9.90$ & 0.139 & 2.57 & $1.37-4.85$ & 0.003 & 2.37 & $0.75-7.43$ & 0.140 & 1.64 & $0.61-4.42$ & 0.327 \\
\hline
\end{tabular}

ALL, acute lymphoblast leukemia; NHL, Non- Hodgkin leukemia; PCNSL, primary central nervous system lymphoma; AML, acute myeloid leukemia

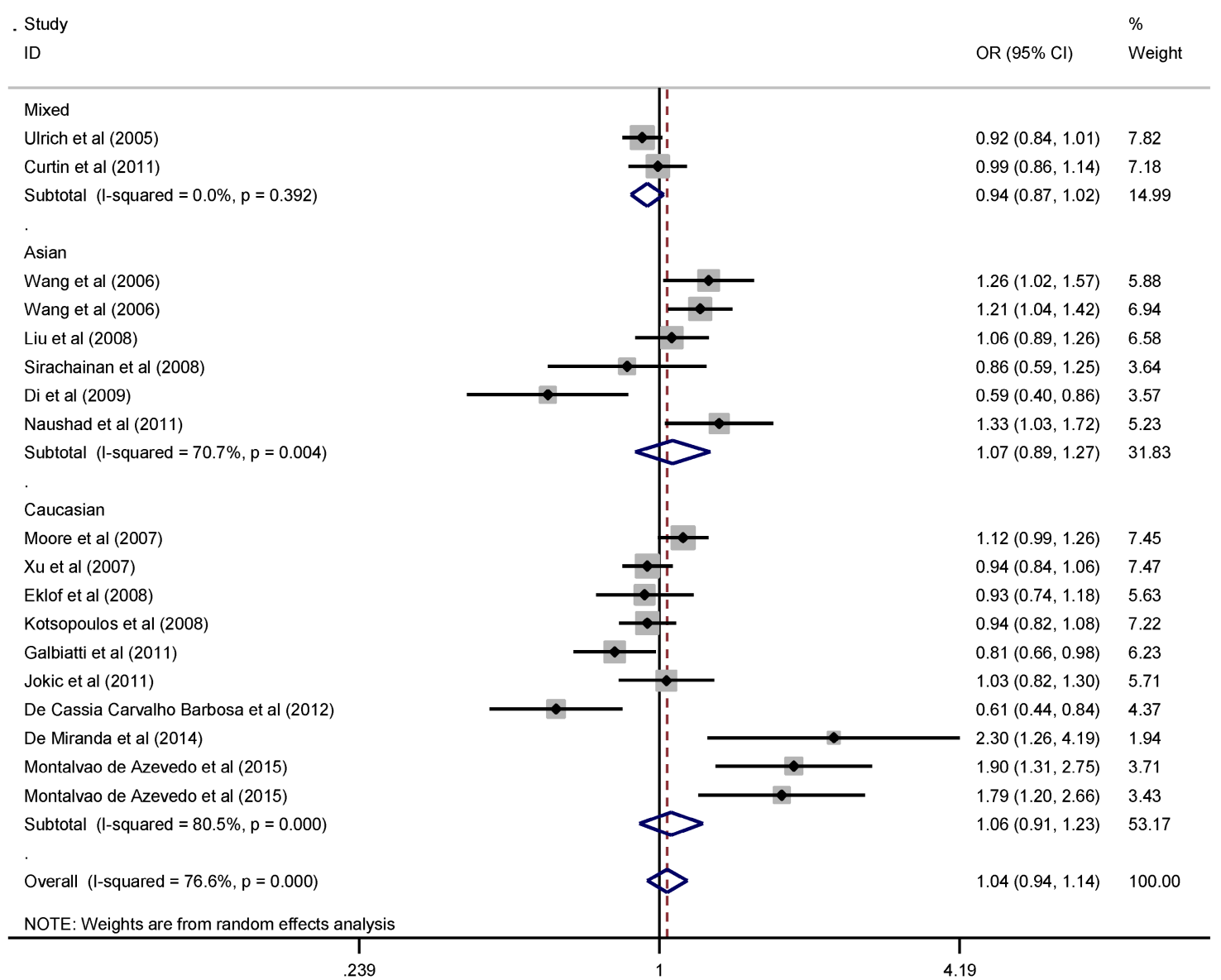

Figure 2. Forest plot of solid cancer risk related with RFCI G80A polymorphism stratified by ethnicity in allele model (A vs. G) 


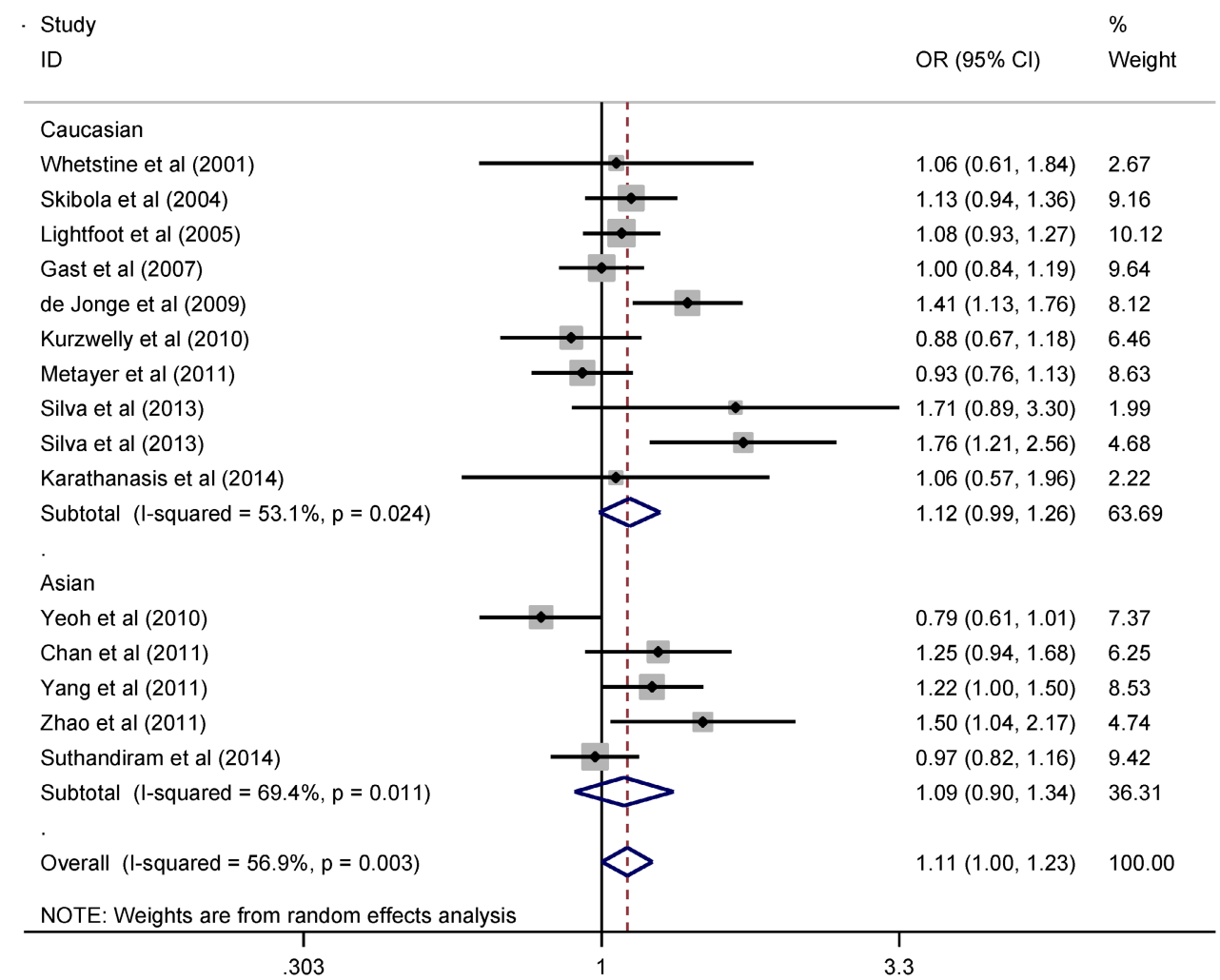

Figure 3. Forest plot of hematological malignance risk related with $R F C I$ G80A polymorphism stratified by ethnicity in allele model (A vs. G)

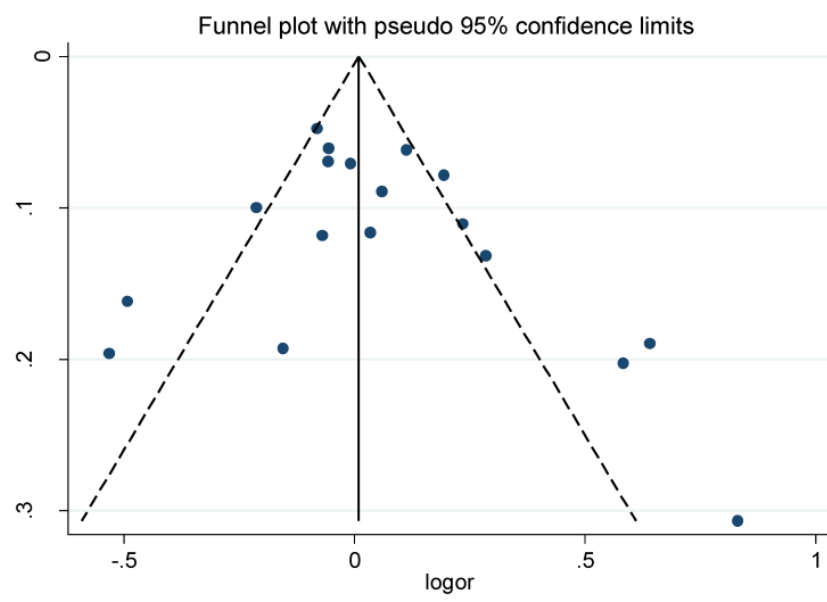

Figure 4. Funnel plot for RFCI G80A polymorphism and solid cancer risk

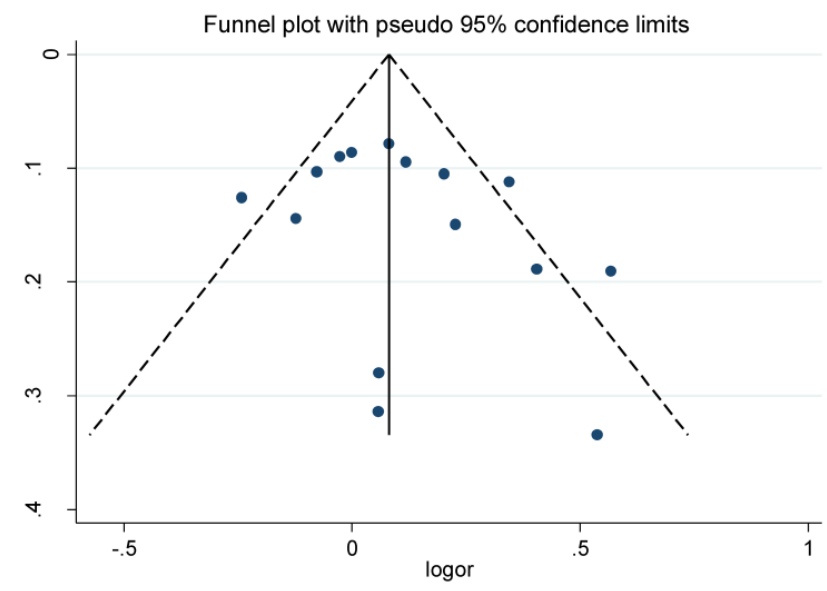

Figure 5. Funnel plot for $\mathrm{RFCl}$ G80A polymorphism and hematological malignance risk

\section{Discussion}

RFC is a typical facilitative transmembrane protein delivering 5-methyltetrahydrofolate from plasma into cells. The dysfunction of RFC has been shown to be related to several disease such as neural tube defects [33], congenital heart defect [34], Alzheimer's Disease [35] and homocysteinemia [36]. Moreover, RFC is also responsible for transporting Methotrexate from extracellular fluid into intracellular fluid, which is an effective treatment for rheumatoid arthritis and acute lymphoblastic leukemia. Although RFC1 G80A polymorphism, leading to a histidine-to-arginine substitution at position 27 of the RFC protein, was first identified in as early as 2000 [36], the effect of this alteration is not fully clarified. Chango et al. [36] indicated that individuals carrying AA genotype had higher plasma folate levels than those carrying GG genotype. Recently, increasing evidences have highlighted the importance of RFC1 G80A polymorphism in the pathogenesis of malignance [37-39]. 
To the best of our knowledge, this is the first meta-analysis focusing on the association of RFC1 G80A polymorphism and the susceptibility of solid cancer. Overall, there was no significant association between the RFC1 G80A polymorphism and solid cancers which was consistent with most of previously published results. On the contrary, some other studies considered RFC1 G80A polymorphism as a risk factor for tumorigenesis. The controversial results of these studies might be partially due to the variations among the different populations. In recent years, increasing researches have investigated the relationship of RFC1 G80A polymorphism and cancer risk; however, the association remains inconclusive. Thus, it is urgent to perform a pooled analysis to clarify the association of interest and give a general envisage of the impact of RFC1 G80A polymorphism on tumorigenesis. In part, this conclusion maybe results from the small sample size in each study. Moreover, a significantly decreased risk of digestive system cancer related to RFC1 G80A polymorphism was observed. Surprisingly, in the studies conducted by Xu et al. [28], Di et al. [40] and Galbiatti et al. [41] AA genotype was considered as wild type, while in the majority of studies GG genotype was regarded as wild type. This discrepancy may lead to conflicting results which may affect the relationship between RFC1 G80A polymorphism and susceptibility of solid cancer in the pooled analysis.

Previous studies have shown that RFC1 G80A polymorphism is related to children acute lymphoblastic leukemia, and this polymorphism may affect the prognosis of acute lymphoblastic leukemia treated with MTX [18, 20]. Similarly, our meta-analysis demonstrated that the studied polymorphism increased the risk of hematological malignance. Koppen et al. [42] and Vijayakrishnan et al. [43] also performed comprehensive analysis on the influence of folate-related gene polymorphisms including the effect of RFC1 G80A polymorphism on susceptibility to leukemia. Koppen et al. [42] failed to find clear association between RFC1 G80A polymorphism and acute lymphoblastic leukemia partly because only one relevant study was included in their meta-analysis. Vijayakrishnan et al. [43] indicated that RFC1 G80A polymorphism was related with acute lymphoblastic leukemia. Compared to the two previous meta-analyses, our study included more eligible studies and provided a more comprehensive and powerful evaluation on the relationship between RFC1 G80A polymorphism and hematological malignance. In the stratification analysis, RFC1 G80A polymorphism was found to be associated with increased leukemia risk in Caucasians under the heterozygous and dominant model, implying the interaction of the ethnic back- ground and genetic variation in leukemia tumorigenesis. As for cancer type, RFC1 G80A polymorphism was associated with acute lymphoblastic leukemia under the heterozygous and dominant model, but not non-Hodgkin lymphoma. These results suggested that the RFC1 G80A polymorphism may play a different role in the pathogenesis of different type of hematological malignance. Besides, due to relatively small sample size of homozygous genotype AA carriers, the data presented in our meta-analysis cannot demonstrate more severe phenotype in homozygous non-synonymous mutation carriers than heterozygous carriers.

Despite the interesting results in our meta-analysis, several limitations of the current study should be acknowledged. First, this meta-analysis only included published studies so that potential publication bias might not be avoided. Second, the influence of a single genetic variant on tumorigenesis is complicated by the gene-gene or gene-environment, which may lead to an unmeasurable deviation while evaluating the relationship between RFC1 G80A polymorphism and cancer risk in this meta-analysis. Third, we performed this meta-analysis with crude ORs since studies included in this meta-analysis lacked sufficient data for adjustment for confounding factors, which might affect the stability of our results. Last, random effect model were used in some genetic models, which might present unstable results. Therefore, validation for our findings from large, well-designed studies is needed in the future.

In conclusion, the comprehensive meta-analysis confirmed the notion that RFC1 G80A polymorphism may play a significant role in hematopoietic system malignance. In addition, the relationship between RFC1 G80A polymorphism and cancer grade and patient prognosis can be a promising research to clarify the role of RFC1 G80A polymorphism in pathogenesis of cancer. Although the mechanism of how RFC1 G80A polymorphism contributes to cancer risk is not entirely clear, it is may be used as a potential biomarker for cancer diagnosis in the future.

\section{Acknowledgements}

This work was supported by the National Natural Scientific Foundation of China (No. 81172077).

We thank Huile Zhong (Guangdong University of Foreign Studies, Guangzhou, China) for polishing and editing the manuscript.

\section{Competing Interests}

The authors have declared that no competing interest exists. 


\section{References}

1. Siegel RL, Miller KD, Jemal A. Cancer statistics, 2015. CA Cancer J Clin. 2015; 65: 5-29.

2. Maddock CR. Environment and heredity factors in carcinoma of the stomach. Br J Cancer. 1966; 20: 660-9.

3. Hanahan D, Weinberg RA. Hallmarks of cancer: the next generation. Cell. 2011; 144: 646-74.

4. Ramaekers VT, Thony B, Sequeira JM, Ansseau M, Philippe P, Boemer F, et al. Folinic acid treatment for schizophrenia associated with folate receptor autoantibodies. Mol Genet Metab. 2014; 113: 307-14

5. Chang SC, Chang PY, Butler B, Goldstein BY, Mu L, Cai L, et al. Single nucleotide polymorphisms of one-carbon metabolism and cancers of the esophagus, stomach, and liver in a Chinese population. PloS one. 2014; 9: e109235.

6. Fiorito G, Guarrera S, Valle C, Ricceri F, Russo A, Grioni S, et al. B-vitamins intake, DNA-methylation of One Carbon Metabolism and homocysteine pathway genes and myocardial infarction risk: the EPICOR study. Nutr Metab Cardiovasc Dis. 2014; 24: 483-8.

7. Iskandar BJ, Rizk E, Meier B, Hariharan N, Bottiglieri T, Finnell RH, et al. Folate regulation of axonal regeneration in the rodent central nervous system through DNA methylation. J Clin Invest. 2010; 120: 1603-16.

8. Li W, Yu M, Luo S, Liu H, Gao Y, Wilson JX, et al. DNA methyltransferase mediates dose-dependent stimulation of neural stem cell proliferation by folate. J Nutr Biochem. 2013; 24: 1295-301.

9. Thaler CJ. Folate Metabolism and Human Reproduction. Geburtshilfe Frauenheilkd. 2014; 74: 845-51.

10. French AE, Grant R, Weitzman S, Ray JG, Vermeulen MJ, Sung L, et al. Folic acid food fortification is associated with a decline in neuroblastoma. Clin Pharmacol Ther. 2003; 74: 288-94

11. Sohn KJ, Jang H, Campan M, Weisenberger DJ, Dickhout J, Wang YC, et al. The methylenetetrahydrofolate reductase $\mathrm{C} 677 \mathrm{~T}$ mutation induces cell-specific changes in genomic DNA methylation and uracil misincorporation: a possible molecular basis for the site-specific cancer risk modification. Int J Cancer. 2009; 124: 1999-2005.

12. He J, Liao XY, Zhu JH, Xue WQ, Shen GP, Huang SY, et al. Association of MTHFR C677T and A1298C polymorphisms with non-Hodgkin lymphoma susceptibility: evidence from a meta-analysis. Sci Rep. 2014; 4: 6159.

13. He J, Wang F, Zhu JH, Chen W, Cui Z, Jia WH. No association between MTR rs1805087 A > G polymorphism and non-Hodgkin lymphoma susceptibility: evidence from 11486 subjects. Leuk Lymphoma. 2015; 56: 763-7.

14. Salerno P, Bianchi F, Pierini A, Baldi F, Carbone P, Mantovani A, et al. [Folic acid and congenital malformation: scientific evidence and public health strategies]. Ann Ig. 2008; 20: 519-30.

15. Matherly LH, Hou Z, Deng Y. Human reduced folate carrier: translation of basic biology to cancer etiology and therapy. Cancer Metastasis Rev. 2007; 26: 111-28.

16. Kung TN, Dennis J, Ma Y, Xie G, Bykerk V, Pope J, et al. RFC1 80G>A is a genetic determinant of methotrexate efficacy in rheumatoid arthritis: a human genome epidemiologic review and meta-analysis of observational studies. Arthritis Rheumatol. 2014; 66: 1111-20.

17. Goldman ID, Matherly LH. The cellular pharmacology of methotrexate. Pharmacol Ther. 1985; 28: 77-102.

18. Gregers J, Christensen IJ, Dalhoff K, Lausen B, Schroeder H, Rosthoej S, et al. The association of reduced folate carrier $80 \mathrm{G}>\mathrm{A}$ polymorphism to outcome in childhood acute lymphoblastic leukemia interacts with chromosome 21 copy number. Blood. 2010; 115: 4671-7.

19. Yates Z, Lucock M. G80A reduced folate carrier SNP modulates cellular uptake of folate and affords protection against thrombosis via a non homocysteine related mechanism. Life Sci. 2005; 77: 2735-42.

20. Chan JY, Ugrasena DG, Lum DW, Lu Y, Yeoh AE. Xenobiotic and folate pathway gene polymorphisms and risk of childhood acute lymphoblastic leukaemia in Javanese children. Hematol Oncol. 2011; 29: 116-23.

21. Metayer C, Scelo G, Chokkalingam AP, Barcellos LF, Aldrich MC, Chang JS, et al. Genetic variants in the folate pathway and risk of childhood acute lymphoblastic leukemia. Cancer Causes Control. 2011; 22: 1243-58.

22. Ulrich CM, Curtin K, Potter JD, Bigler J, Caan B, Slattery ML. Polymorphisms in the reduced folate carrier, thymidylate synthase, or methionine synthase and risk of colon cancer. Cancer Epidemiol Biomarkers Prev. 2005; 14: 2509-16.

23. Eklof V, Van Guelpen B, Hultdin J, Johansson I, Hallmans G, Palmqvist R. The reduced folate carrier (RFC1) $80 \mathrm{G}>\mathrm{A}$ and folate hydrolase 1 (FOLH1) 1561C > T polymorphisms and the risk of colorectal cancer: A nested case-referent study. Scand J Clin Lab Invest. 2008; 68: 393-401.

24. Curtin K, Ulrich CM, Samowitz WS, Wolff RK, Duggan DJ, Makar KW, et al. Candidate pathway polymorphisms in one-carbon metabolism and risk of rectal tumor mutations. Int J Mol Epidemiol Genet. 2011; 2: 1-8.

25. Jokic M, Brcic-Kostic K, Stefulj J, Ivkovic TC, Bozo L, Gamulin M, et al. Association of MTHFR, MTR, MTRR, RFC1, and DHFR gene polymorphisms with susceptibility to sporadic colon cancer. DNA Cell Biol. 2011; 30: 771-6.

26. Wang L, Chen W, Wang J, Tan Y, Zhou Y, Ding W, et al. Reduced folate carrier gene G80A polymorphism is associated with an increased risk of gastroesophageal cancers in a chinese population. Eur J Cancer. 2006; 42: 3206-11.

27. Moore LE, Malats N, Rothman N, Real FX, Kogevinas M, Karami S, et al. Polymorphisms in one-carbon metabolism and trans-sulfuration pathway genes and susceptibility to bladder cancer. Int J Cancer. 2007; 120: 2452-8.
28. Xu X, Gammon MD, Zhang H, Wetmur JG, Rao M, Teitelbaum SL, et al. Polymorphisms of one-carbon-metabolizing genes and risk of breast cancer in a population-based study. Carcinogenesis. 2007; 28: 1504-9.

29. Kotsopoulos J, Zhang WW, Zhang S, McCready D, Trudeau M, Zhang P, et al. Polymorphisms in folate metabolizing enzymes and transport proteins and the risk of breast cancer. Breast Cancer Res Treat. 2008; 112: 585-93.

30. Naushad SM, Pavani A, Digumarti RR, Gottumukkala SR, Kutala VK. Epistatic interactions between loci of one-carbon metabolism modulate susceptibility to breast cancer. Mol Biol Rep. 2011; 38: 4893-901.

31. De Cassia Carvalho Barbosa R, Menezes DC, Freire TFV, Sales DC, Alencar VHM, Rabenhorst SHB. Associations of polymorphisms of folate cycle enzymes and risk of breast cancer in a Brazilian population are age dependent. Mol Biol Rep. 2012; 39: 4899-907.

32. Sirachainan N, Wongruangsri S, Kajanachumpol S, Pakakasama S, Visudtibhan A, Nuchprayoon I, et al. Folate pathway genetic polymorphisms and susceptibility of central nervous system tumors in Thai children. Cancer Detect Prev. 2008; 32: 72-8.

33. Shang Y, Zhao H, Niu B, Li WI, Zhou R, Zhang T, et al. Correlation of polymorphism of MTHFRs and RFC-1 genes with neural tube defects in China. Birth Defects Res A Clin Mol Teratol. 2008; 82: 3-7.

34. Pei L, Zhu H, Zhu J, Ren A, Finnell RH, Li Z. Genetic variation of infant reduced folate carrier (A80G) and risk of orofacial defects and congenital heart defects in China. Ann Epidemiol. 2006; 16: 352-6.

35. Bi XH, Zhao HL, Zhang ZX, Zhang JW. Association of RFC1 A80G and MTHFR C677T polymorphisms with Alzheimer's disease. Neurobiol Aging. 2009; 30: 1601-7.

36. Chango A, Emery-Fillon N, de Courcy GP, Lambert D, Pfister M, Rosenblatt DS, et al. A polymorphism (80G->A) in the reduced folate carrier gene and its associations with folate status and homocysteinemia. Mol Genet Metab. 2000; 70: 310-5.

37. De Miranda DO, Barros JEXS, Vieira MMS, Lima ELS, Moraes VLL, Da Silva $\mathrm{HA}$, et al. Reduced folate carrier-1 G80a gene polymorphism is associated with neuroblastoma's development. Mol Biol Rep. 2014; 41: 5069-75.

38. Silva RM, Fontes AC, Silva KA, Sant'Ana TA, Ramos FJ, Marques-Salles Tde I, et al. Polymorphisms involved in folate metabolism pathways and the risk of the development of childhood acute leukemia. Genet Test Mol Biomarkers. 2013; 17: 147-52.

39. Montalvao de Azevedo R, Vasconcelos GM, Vargas FR, Thuler LC, Pombo-de-Oliveira MS, de Camargo B. RFC-1 80G>A Polymorphism in Case-Mother/Control-Mother Dyads Is Associated with Risk of Nephroblastoma and Neuroblastoma. Genet Test Mol Biomarkers. 2014.

40. Di JJ, Wang JT, Ding L, Wang ZM, Gao ES. A case-control study on the association of RFC-1 polymorphism and cervical cancer. Zhonghua Liu Xing Bing Xue Za Zhi. 2009; 30: 189-91.

41. Galbiatti ALS, Ruiz MT, Rezende Pinto D, Raposo LS, Maniglia JV, Pavarino-Bertelli EC, et al. A80G polymorphism of reduced folate carrier 1 (RFC1) gene and head and neck squamous cell carcinoma etiology in Brazilian population. Mol Biol Rep. 2011; 38: 1071-8.

42. Koppen IJ, Hermans FJ, Kaspers GJ. Folate related gene polymorphisms and susceptibility to develop childhood acute lymphoblastic leukaemia. Br J Haematol. 2010; 148: 3-14.

43. Vijayakrishnan J, Houlston RS. Candidate gene association studies and risk of childhood acute lymphoblastic leukemia: a systematic review and meta-analysis. Haematologica. 2010; 95: 1405-14

44. Whetstine JR, Gifford AJ, Witt T, Liu XY, Flatley RM, Norris M, et al. Single nucleotide polymorphisms in the human reduced folate carrier: characterization of a high-frequency G/A variant at position 80 and transport properties of the His(27) and $\operatorname{Arg}(27)$ carriers. Clin Cancer Res. 2001; 7: 3416-22.

45. Skibola CF, Forrest MS, Coppede F, Agana L, Hubbard A, Smith MT, et al. Polymorphisms and haplotypes in folate-metabolizing genes and risk of non-Hodgkin lymphoma. Blood. 2004; 104: 2155-62.

46. Lightfoot TJ, Skibola CF, Willett EV, Skibola DR, Allan JM, Coppede F, et al. Risk of non-Hodgkin lymphoma associated with polymorphisms in folate-metabolizing genes. Cancer Epidemiol Biomarkers Prev. 2005; 14: 2999-3003.

47. Gast A, Bermejo JL, Flohr T, Stanulla M, Burwinkel B, Schrappe M, et al. Folate metabolic gene polymorphisms and childhood acute lymphoblastic leukemia: a case-control study. Leukemia. 2007; 21: 320-5.

48. Liu H, Jin G, Wang H, Wu W, Liu Y, Qian J, et al. Association of polymorphisms in one-carbon metabolizing genes and lung cancer risk: a case-control study in Chinese population. Lung Cancer. 2008; 61: 21-9.

49. de Jonge R, Tissing WI, Hooijberg JH, Jansen G, Kaspers GJ, Lindemans J, et al. Polymorphisms in folate-related genes and risk of pediatric acute lymphoblastic leukemia. Blood. 2009; 113: 2284-9.

50. Kurzwelly D, Knop S, Guenther M, Loeffler J, Korfel A, Thiel E, et al. Genetic variants of folate and methionine metabolism and PCNSL incidence in a German patient population. J Neurooncol. 2010; 100: 187-92.

51. Yeoh AE, Lu Y, Chan JY, Chan YH, Ariffin H, Kham SK, et al. Genetic susceptibility to childhood acute lymphoblastic leukemia shows protection in Malay boys: results from the Malaysia-Singapore ALL Study Group. Leuk Res. 2010; 34: 276-83.

52. Yang L, Liu L, Wang J, Qiu L, Mi Y, Ma X, et al. Polymorphisms in folate-related genes: impact on risk of adult acute lymphoblastic leukemia rather than pediatric in Han Chinese. Leuk Lymphoma. 2011; 52: 1770-6. 
53. Zhao W, Yue LJ, Chen XW. [Association of single nucleotide polymorphism of reduced folate carrier gene with susceptibility to acute leukemia]. Zhonghua Yi Xue Yi Chuan Xue Za Zhi. 2011; 28: 446-9.

54. Karathanasis NV, Stiakaki E, Goulielmos G, Kalmanti M. The effect of RFC G80A polymorphism in Cretan children with acute lymphoblastic leukemia and its interaction with MTHFR C677T and A1298C polymorphisms. Int J Lab Hematol. 2014; 36: 425-30.

55. Suthandiram S, Gan GG, Zain SM, Bee PC, Lian LH, Chang KM, et al. Genetic polymorphisms in the one-carbon metabolism pathway genes and susceptibility to non-Hodgkin lymphoma. Tumour Biol. 2014. 